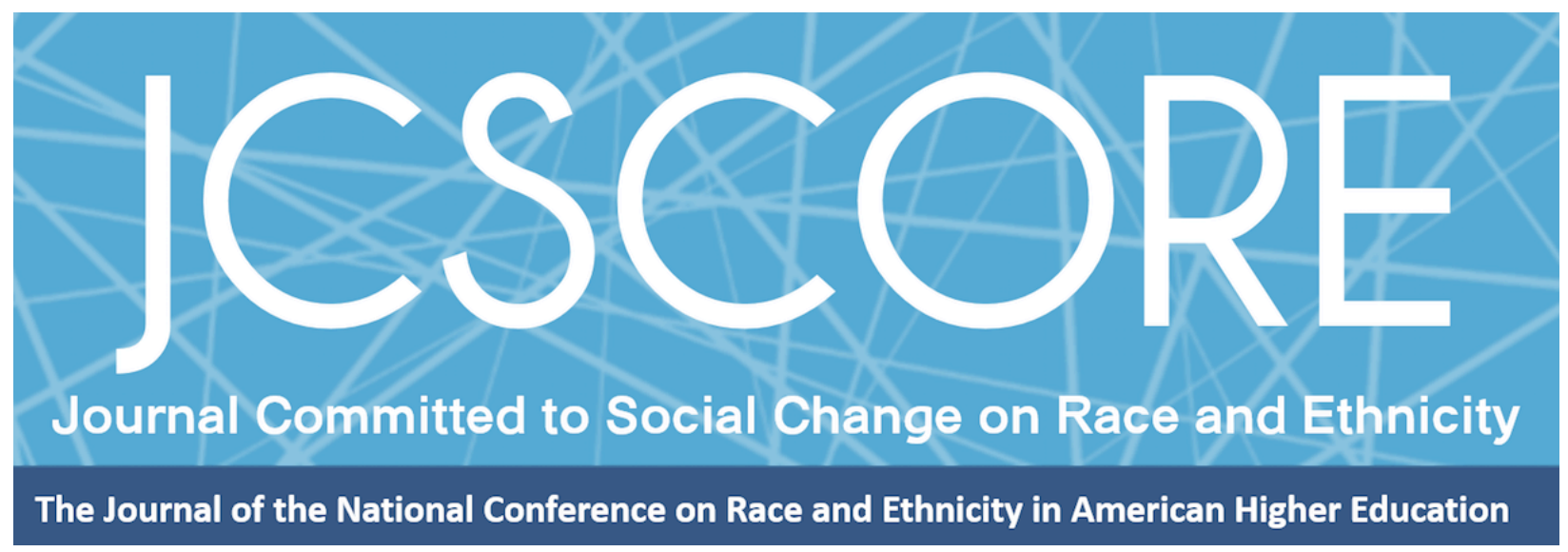

\title{
DISABILITY JUSTICE, RACE \& EDUCATION: ARTWORK
}

\author{
Diana Lopez \\ Independent Scholar and Artist
}

Journal Committed to Social Change on Race and Ethnicity

Volume 6, Issue 1 | 2020

\author{
Copyright and Open Access \\ (C) 2020 Diana Lopez \\ (c) (i) (2)
}

This work is licensed under a Creative Commons Attribution-NonCommercial-ShareAlike 4.0 International License. Permission of the authors is required for distribution and for all derivative works, including compilations and translations. Quoting small sections of text is allowed as long as there is appropriate attribution and the article is used for non-commercial purposes.

The Journal Committed to Social Change on Race and Ethnicity (ISSN 2642-2387) is published by the National Conference on Race and Ethnicity (NCORE), a production of the University of Oklahoma, in partnership with the University of Oklahoma Libraries.

The Southwest Center for Human Relations Studies • The University of Oklahoma's College of Continuing Education 


\title{
Disability Justice, Race \& Education: Artwork
}

\author{
Diana Lopez \\ Independent Scholar and Artist
}

Diana Lopez is a self-taught Deaf artist from Los Angeles, CA. She has been a freelance artist over the past five years. Her work is involved the complexity of human emotions that they are difficult to put in words. Diana is able to express those deeply feelings through colorful brushstrokes and textured paintings, where it can be felt, touched and seen through sensory experiences. Her deafness is a huge part of her identity. You can find her work on Instagram @duppet_puppet and on Facebook @DuppetPuppet.

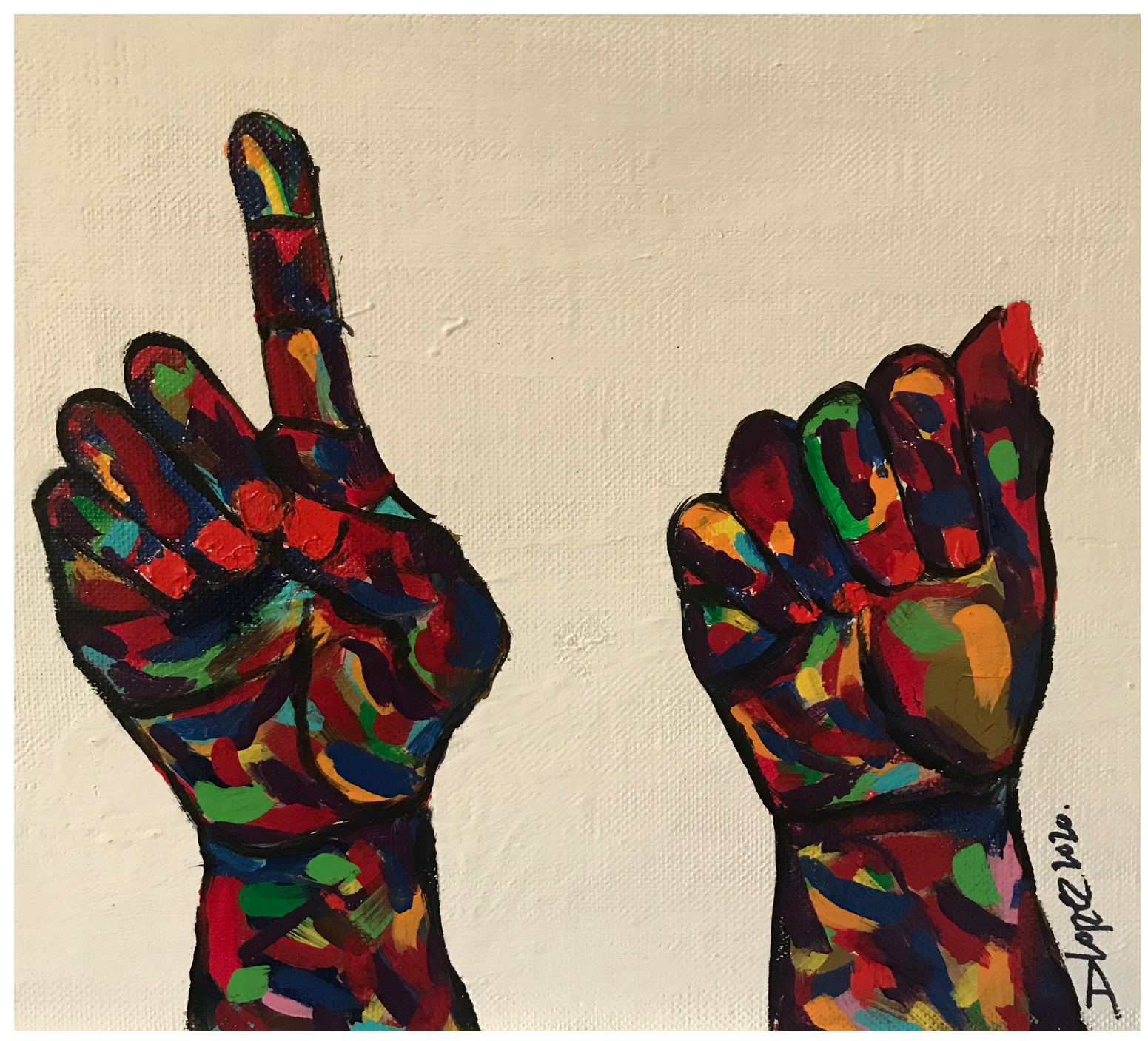

